\title{
Social complexity from within: how individuals experience the structure and organization of their groups
}

\author{
Filippo Aureli ${ }^{1,2}$ (D) Gabriele Schino ${ }^{3}$
}

Received: 18 February 2018 /Revised: 12 August 2018 / Accepted: 12 November 2018 / Published online: 19 January 2019

(C) The Author(s) 2019

\begin{abstract}
We argue that the study of social complexity can follow two different approaches, based on how it is seen from the outside or on how it is experienced from within. Recent focus has been on the former with social complexity emerging from the interactions of group members. Here, we take the view from within and deal with the social complexity that individual group members may experience, exploring complexity arising from aspects of the social structure and social organization. We review a variety of sources of social complexity in terms of variation between and within social relationships, variation in opportunities to interact with different group members, and the role of third parties. We then examine how individuals can cope with the social complexity they face. We conclude that a refined view of social relationships at different levels is needed to study the social complexity faced by individual group members and emphasize the potential contribution of the view from within to the study of social complexity and cognition.
\end{abstract}

\section{Significance statement}

Animals may experience different degrees of complexity in their social groups. Instead of viewing social complexity as an emergent property of the interactions exchanged by group members, we focus on the social complexity individual group members may experience. We examine how aspects of social structure and social organization, such as the variation between and within social relationships, the variation in opportunities to interact with different group members, and the role of third parties, could create challenges and sources of complexity for individual group members. We then evaluate how emotions and cognitive abilities could be used by animals of different species to navigate the social complexity they experience and make appropriate decisions. We show that there are neglected sources of social complexity related to social relationships that derive from them changing over time and consisting of different components. We conclude by emphasizing that a change in perspective is needed to study how cognition is linked to the social complexity individual group members may experience.

Keywords Differentiation $\cdot$ Emotion $\cdot$ Fission-fusion dynamics $\cdot$ Social cognition $\cdot$ Social relationship $\cdot$ Third party

Communicated by D. Lukas

This article is a contribution to the Topical Collection Social complexity: patterns, processes, and evolution - Guest Editors: Peter Kappeler, Susanne Shultz, Tim Clutton-Brock, and Dieter Lukas

Filippo Aureli

faureli@uv.mx; f.aureli@ljmu.ac.uk

1 Instituto de Neuroetologia, Universidad Veracruzana, 91190 Xalapa, Veracruz, Mexico

2 Research Centre in Evolutionary Anthropology and Palaeoecology, Liverpool John Moores University, Liverpool, UK

3 Istituto di Scienze e Tecnologie della Cognizione, Consiglio Nazionale delle Ricerche, Rome, Italy

\section{Introduction}

Although there is no generally accepted definition of complexity (Chu et al. 2003; Kappeler 2019, topical collection on Social complexity), there is a general consensus across disciplines that complexity emerges from the interaction of non-complex elements, which are non-identical and interact in different ways, often following simple rules (Nadel and Stein 1991; Bascompte and Solé 1995; Chialvo 2010; Johnson 2009). Social complexity can be viewed in a similar way, although this is not often explicitly stated (Freeberg et al. 2012). For example, the coordinated movements of bird flocks and fish schools and the impressive nests built by social insects are interpreted as complex emergent properties of simple 
individual actions (Shaw 1970; Bonabeau et al. 1997; Parrish and Edelstein-Keshet 1999; Ballerini et al. 2008). Computational models have been used to capture these observable emergent properties and the self-organizing nature of social groups giving rise to social complexity (Reynolds 1987; Ramos-Fernandez et al. 2006; Hemelrijk 2013; Storms et al. 2019, topical collection on Social complexity).

This approach to the study of social complexity emphasizes the emerging outcome. It is like the scientist viewing a primate group, an ungulate herd, a bird flock, or a fish school, and being intrigued by its seemingly complex features. But does the single individual monkey, deer, starling, or herring view it the same way? It is unlikely, as they are part of the emergent complexity. In the same way, we cannot appreciate the overall outcome of a crowd moving if we are part of the crowd. Thus, the social complexity emerging from the interactions between group members is not the same social complexity experienced by the individuals interacting. There is therefore a social complexity that can be viewed from the outside and a social complexity that can be experienced from within (cf. Fischer et al. 2017; Lukas and Clutton-Brock 2019; Weiss et al. 2019, topical collection on Social complexity). These two ways of viewing social complexity are complementary, and none of them is inherently better than the other, much as Tinbergen's (1963) four "questions" provide complementary approaches to the interpretation of biological phenomena. Viewing the same phenomenon from the individual perspective or from a more global perspective is common practice. For example, parasitology studies of the selective pressures imposed by parasites emphasize the individual-level consequences of behavioral variation, whereas epidemiological studies of disease spread and prevalence emphasize the population-level consequences in terms of population growth and extinction risks (Altizer et al. 2003). An example regarding complexity is that of ant colonies in which more complex societies are characterized by lower individual complexity (Anderson and McShea 2001). Thus, in the case of social complexity, there are very valid reasons to study the emergent complexity viewed from the outside, as several of the contributions to this special issue highlight (e.g., Fuentes-González and Martins 2019; He et al. 2019; Storms et al. 2019, all in topical collection on Social complexity). However, here, we take the view from within and deal with the social complexity that a single individual may experience.

Recently, Freeberg et al. (2012) defined complex social systems as those in which individuals frequently interact in many different contexts with many different individuals, and often repeatedly interact with many of the same individuals over time. Although this definition focuses on the complexity of the emergent social system, it underlines several elements that individual group members face within the social system. The definition emphasizes aspects, such as "frequently," "different," and "many," that may be critical for the individual group member's perspective. A more overt stance toward the individual perspective of social complexity was made by Bergman and Beehner (2015). In their quest for a measure of social complexity meaningful in the context of social $\operatorname{cog}$ nition, Bergman and Beehner (2015) proposed that social complexity should be measured as the number of differentiated relationships that individuals have. We develop this perspective further.

There are many social groupings in which membership is highly variable and the number of members is so large, that it is impossible for a single member to recognize each of the others (e.g., loose herds of wildebeest: Talbot and Talbot 1963). Still, simple rules followed by individual members in these groupings may result in emergent social complexity (Gueron and Levin 1993). The situation is likely very different when the social grouping is based on demographically stable membership and individual recognition by each member of all other members. These characteristics allow group members to develop social relationships that can be beneficial (cf. individualized societies: de Waal and Tyack 2003; bonded social systems: Dunbar 2012). Under these circumstances, individuals may tune their social behavior in relation to the identity of some or all partners with whom they interact. This possibility permits differentiation among the social relationships an individual has, with social decision-making becoming more demanding, the more her social relationships are differentiated.

Let us use dominance as an example. We can infer the dominance hierarchy of a group by the patterning of the dominance relationships between group members, which are based on the patterning of the dominance interactions (e.g., aggression, spatial displacements, submission, avoidance) between each pair of individuals (Hinde 1978). In this respect, the dominance hierarchy is an emergent property of the social interactions between group members, being a good example of social complexity viewed from the outside. But what about the view from within? Do individual group members face complexity when they interact within a dominance hierarchy? The answer is not straightforward as it depends on the elements on which individuals make their decisions about interacting. If individuals simply interact submissively toward a given set of group members (the "dominants") and assertively toward another set of group members (the "subordinates"), there is not much differentiation among their social relationships. However, if individuals interact with different group members in relation to their relative position in the dominance hierarchy (e.g., they groom others in relation to their dominance rank: Schino 2001), the degree of relationship differentiation is higher and the assessment is more demanding, as it requires a finer tuning of behavior and the recognition of the relative rank positions of the group members (Bergman et al. 2003). Furthermore, if individuals take into account the possibility that third parties may intervene in aggressive interactions (Harcourt and de Waal 1992), and even consider the potential supporters' 
dominance rank relative to the opponent's dominance rank before engaging in a competitive interaction and recruiting supporters (Silk 1999; Perry et al. 2004; Schino et al. 2006), individuals face an even more demanding assessment. Under these circumstances, each individual's behavior in the competitive interaction would be affected not only by the partner's behavior, but also by other group members' previous and current behavior. Such social environments are regarded as complex adaptive systems that produce distinct selective pressures, which cannot be observed in species with unstable group membership (Kutsukake 2009).

As an extreme example of the differences between social complexity as viewed from the outside and social complexity as viewed from within, i.e., from the individual group member, we can consider the eusocial insects. Their societies are often presented as extremely complex (Kapheim 2019; Kappeler 2019, both in topical collection on Social complexity). We believe that this is true when we use the view from the outside. However, the individual bee, wasp, or ant has only to differentiate among a few castes in order to make appropriate social decisions, while the identity of individual group members is irrelevant (although some species are capable of individual recognition: Sheehan et al. 2014). Viewed from within, a bee, wasp, or ant society must be relatively simple.

The degree of differentiation of social relationships is thus the critical aspect that defines social complexity as seen from within. Here, we take this view and examine the social complexity that a single individual may experience. We follow Kappeler and van Schaik's (2002) definitions of the components of social systems, in which the term "social structure" refers to the pattern of social interactions and the resulting relationships between group members, and the term "social organization" refers to the size, sexual composition, and spatiotemporal cohesion of the group (see also Kappeler 2019, topical collection on Social complexity). We explore complexity arising from aspects of the social structure and from aspects of the social organization. First, we review a variety of sources of social complexity in terms of variation between and within social relationships, variation in opportunities to interact with different group members, and the role of third parties. Second, we examine how individuals can cope with the social complexity they face. Finally, we propose that a dynamic view of social relationships at different levels is needed to study the social complexity faced by individual group members and emphasize the potential contribution of the view from within to the study of social complexity and cognition.

\section{Aspects of social structure relevant to social complexity}

Hinde's $(1976,1979)$ framework highlights that social structure is an emergent property. In this framework, the observable components are the social interactions, which can be described in terms of content (what behavior is exchanged, e.g., grooming, play, or aggression) and qualifiers (the way the behavior is exchanged, e.g., rapidly, gently, or intensively). When two individuals have a series of interactions, any one interaction may affect the subsequent ones and their unique history of interactions forms their social relationship. According to this view, social relationships are emergent phenomena derived from the patterning of interactions between individuals across time (Aureli et al. 2012), and social structures are emergent phenomena derived from the patterning of social relationships between individuals.

According to Hinde's $(1976,1979)$ framework, a social relationship can be described in terms of the content and the qualifiers of the interactions and the relative frequencies and patterning of those interactions over time. For example, two individuals that groom each other often and attack each other little have a different relationship from two individuals that groom each other rarely but attack each other often. However, the relative frequencies of the interactions are not sufficient to distinguish types of relationships. Two individuals may have exchanged grooming frequently last week and exchanged attacks frequently this week. This relationship would however differ from one with the same frequencies of the two types of interactions, but characterized by each attack being followed by a grooming bout (i.e., a different patterning). Furthermore, not only is a social relationship between two individuals affected by the interactions they exchange, but their interactions are affected by the relationship. As the previous history of interactions between two individuals affects the subsequent interactions, their social relationship constrains the way they interact with each other (Hinde 1983a). For example, two individuals interact in a given way in a competitive context depending on their dominance relationship.

Each participant in a relationship also interacts with other group members, and thus has relationships with them. The relationships that two individuals have with other group members affect the relationship that they have with each other (Hinde 1976, Hinde 1983a). Hence, each relationship is part of a network of relationships, i.e., the emergent social structure, which can be described in terms of the properties of the constituent relationships and how these relationships are patterned. In turn, the social structure affects the constituent relationships. For example, a new immigrant individual would form more clear-cut dominance relationships in a group with a stricter dominance hierarchy than in a group with a shallower dominance hierarchy.

As explained above, Hinde's $(1976,1979)$ framework underscores the potential for variation across social relationships and the factors possibly affecting it. We argue the degree of such variation is one of the two main contributors to the complexity an individual faces within a given social structure (the other being variation within social relationships). In the next 
section, we review evidence of variation across social relationships an individual has with different partners and how such a variation can be a source of complexity.

\section{Variation across social relationships}

Animals that live in groups with stable membership can interact in different ways with different group members. When this variation shows temporal consistency and extends across several types of social interactions, animals can be said to have differentiated social relationships (Bashaw et al. 2007). The study of differentiated relationships has been a prominent topic for primatologists (Hinde 1983b), but differentiated relationships are not exclusive to primates (e.g., Reinhardt and Reinhardt 1981; Durrell et al. 2004). The way individuals interact with other group members depends on a variety of characteristics. Some of the most studied characteristics are age, sex, kinship, and dominance rank. For example, in lions (Panthera leo), head rubbing (an affiliative interaction) occurs mostly among males and licking (another affiliative interaction) mostly among females; the latter is strongly influenced by kinship (Matoba et al. 2013).

The degree of complexity individuals face regarding relationship differentiation depends on how individuals take into account the relevant variable. For example, Guilhem et al. (2000) reported that yearling mouflons (Ovis gmelini) rest preferentially in proximity with age-peers. Relationship differentiation, in this case, could be based on a simple binary discrimination (peers vs. non-peers) without the need to distinguish between finer age categories. The situation would be more complex if individuals need to differentiate the way they interact with other group members based on a continuous variable or on multiple (ordered) categories of a variable, such as the different degrees of kinship they share with group members. For example, adult Japanese macaque (Macaca fuscata) females support juvenile group members during aggressive interactions depending on their degree of kinship, with only mothers, grandmothers, and great-grandmothers giving support to their juvenile kin, whereas aunts, grandaunts, and cousins do not (Chapais et al. 2001; cf. Schino et al. 2007). Similarly, spotted hyaenas (Crocuta crocuta) respond to cub vocalizations in relation to their degree of kinship with the cub (Holekamp et al. 1999). Also, a meta-analysis of cooperative breeding in mammals and birds showed that helping is related to the degree of kinship between the individuals involved (Griffin and West 2003).

These examples illustrate that if individuals use continuous or ordinal assessment with multiple sets (i.e., more than two categories) to categorize group members according to a key characteristic, the degree of complexity individuals face while making decisions about interacting is higher than if they simply categorize group members into two sets. The situation is even more complex when individuals need to take into account not only one (e.g., kinship), but multiple characteristics of other group members (e.g., age, sex, kinship, and dominance rank) for effective social interaction. The study of conflict management has shown that a variety of relationship characteristics can affect the likelihood different behavioral mechanisms would take place in the aftermath of an aggressive interaction (Aureli and Waal 2000). For example, the friendly reunion between former opponents soon after an aggressive interaction (labeled reconciliation by de Waal and van Roosmalen 1979) is more likely between kin than nonkin, between individuals that support one another more often, and between group members that exchange affiliation at higher rates (Aureli et al. 1989; Mason et al. 2004; Watts 2006: Palagi et al. 2008; Romero et al. 2009).

Starting from the study of conflict management, Cords and Aureli (2000) proposed a conceptual framework to identify components of relationship quality. This framework is based on how the social interactions exchanged by two individuals can capture the quality of their social relationship. Thus, instead of examining whether kinship or relative dominance rank explains the distribution of social interactions, such as aggression, grooming, coalitions, and reconciliation, across group members, this framework focuses on the emergent relationship quality based on the patterning of social interactions, which may itself be correlated with factors such as the degree of kinship or relative dominance rank. Cords and Aureli (2000) proposed three components of relationship quality: (1) value, which reflects the benefits afforded by the relationship; (2) compatibility, which reflects the degree of tolerance between partners; and (3) security, which reflects the predictability or consistency of interactions between partners over time. These three are not necessarily the only possible components, and they can be replaced or other components can be added to thoroughly illustrate relationship quality in different species (see Silk et al. 2013 for additional components).

To obtain components of relationship quality, we need to start from the social interactions exchanged between group members. Studies of mother-infant relationships pioneered such an approach by using principal component analysis (Simpson and Howe 1980; Schino et al. 1995). Fraser et al. (2008) were the first to apply this approach to social relationships among adult group members. Such an approach involves entering indices based on social interactions (e.g., aggression rates, proportion of time spent in proximity, coefficient of variation of time spent in association, likelihood of support, or food sharing) into a principal component analysis (Aureli et al. 2012). The components extracted by this analysis have loadings for each interaction index, which facilitate labelling of a component (e.g., the label "compatibility" for a component with low loadings for aggression rates and high loadings for the proportion of time spent in proximity), and each dyad entered in the analysis has a value for each 
component, which allows one to test whether the component is correlated with certain relationship characteristics (e.g., kinship and relative dominance rank). Since Fraser et al.'s (2008) research on a zoo group of chimpanzees, this approach has been successfully used for primate and nonprimate species both in captivity and in the wild. For example, similar components were extracted for hand-reared ravens (Corvux corax) housed in a large aviary (Fraser and Bugnyar 2010) and in wild Geoffroy's spider monkeys (Ateles geoffroyi: Busia et al. 2017).

Identifying multiple components of relationship quality based on social interactions emphasizes the challenge individuals may face when making decisions about with whom and how to interact in their group. The challenge depends on the degree of variation across social relationships with other group members and on whether the variation is based on one, a few, or several components of relationship quality. Still, variation not only exists across social relationships. There is also an important source of variation that is within each social relationship.

\section{Variation within social relationships}

Social relationships can change over time. It is useful to distinguish between predictable (developmental) changes and unpredictable changes. The most obvious (and most studied) example of predictable changes in social relationships comes from the development of mother-infant relationships. In macaques and baboons, for example, mothers and newborn infants spend almost $100 \%$ of their time in close body contact, but this percentage decreases as the infant grows older and the mother plays an active role in promoting infant independence (Hinde and White 1974; Altmann 1980). These predictable developmental changes are not free from conflicts between the individuals involved, as the interests of mothers and infants are not perfectly aligned (Trivers 1974). For our purposes, the main point relevant to social complexity to be emphasized is that a mother cannot adopt a fixed behavioral strategy toward her infant, but has to constantly adapt to the changing behavior of the infant, progressively promote its independence, and deal with the conflicts that arise because of the mismatch between her own and the infant's interests, especially during the weaning period.

A less studied example of predictable change in social relationship is the formation of social relationships between initially unfamiliar individuals. The pioneering studies of Kummer (1975) showed how geladas (Theropithecus gelada) that meet for the first time go through a predictable series of interactions, from aggression to presentation and then to affiliation. Similar predicable sequences have been observed in other experimental studies (Ganslosser 1993; Baker and Aureli 2000). The establishment of clear-cut dominance relationships seems to play a critical role in the establishment of more amicable relationships. Uncertainty about dominance could hinder the possibility of affiliative interactions (de Waal 1986; Schino et al. 1990). In the wild, new relationships are formed whenever an individual immigrates into a new group, but this process of relationship formation is much more difficult to study and the available information is sparse. This difficulty derives from the scientists generally missing the first phase of the process when the immigrant individual is mostly peripheral to the study group. This first phase is usually characterized by aggression against the immigrant by residents, especially residents of the same sex of the immigrant. For example, in Geoffroy's spider monkeys in which females are the dispersing sex, resident females are aggressive to newly immigrant females (Asensio et al. 2008; Riveros et al. 2017). If the immigrant female is successful in integrating into the new group, aggression against her declines over time (Riveros et al. 2017). Given that females are interested in other females' young infants and direct friendly interactions toward the mother (Slater et al. 2007), the integration is likely completed after an immigrant female has had her first infant. Again, the main point relevant to social complexity to be emphasized here is the necessity for animals to adapt to the changing nature of their relationships. Every step in the development of the relationship with an initially unknown individual implies a possible change in how the other individual will behave and in how the subject will respond to the behavior of the other individual.

In the examples above, social relationships changed following a relatively predictable pattern. This predictability may make it easier to deal with changes as specific responses to predictable changes can be shaped by natural selection. For example, given the relevant fitness consequences of maternal care, it is likely that selection has provided mothers with a predisposition to progressively modify their behavior toward infants, these progressive modifications being triggered by hormonal changes and by the changes in the physical stimuli provided by the growing infant.

Unpredictable, and often abrupt, changes in social relationships can also occur. For example, major rises or falls in the dominance hierarchy imply correspondingly major changes in the social relationships of the individuals involved. These events are rare, but whoever has observed any dominanceoriented species for a sufficiently long period can remember a few examples. Nevertheless, detailed reports are rare in the literature. One of the best examples comes from the struggles for dominance among males in zoo chimpanzees (de Waal 1982). Major changes in a dominance hierarchy are often associated to changes in the affiliative network, but the extent to which changes in affiliation cause or are caused by changes in dominance is generally unknown and is probably variable (Chapais et al. 1995). The unpredictability and relative rarity of these events make their systematic study difficult. In the context of this review, unpredictable changes make the social 
environment more difficult to navigate as the animal may have neither previous experience of similar events, nor inborn specific responses that had been shaped by natural selection to adapt rapidly to major social changes. As a consequence, groups in which dominance hierarchies change frequently (e.g., among chacma baboon males, Papio hamadryas ursinus: Palombit et al. 2000) may exemplify a social environment that is perceived by group members as more complex than that of more stable groups (e.g., among capuchin monkey males, Sapajus nigritus: Janson et al. 2012).

\section{Do third parties influence dyadic relationships?}

A further layer in the social complexity perceived by the individual animal is added by the influence third parties can have on the social relationship between two individuals. Active interference in the social interactions between other group members has been reported in a number of species. In primates and in other animals, the most studied of such interferences are interventions (both aggressive and peaceful) into ongoing aggressive interactions, supporting either the victim or the aggressor (Harcourt and de Waal 1992; Petit and Thierry 1994; Smith et al. 2010). For example, juvenile macaques and spotted hyenas rise in rank as they approach sexual maturity thanks to the coalitionary support they receive from their kin (Kawai 1958; Chapais 1988; Holekamp et al. 2007). Kin, and especially mothers, are therefore instrumental in the acquisition of dominance rank, and other group members have to take into account the mother's behavior in their interactions with juveniles.

Less well studied is third party interference into the affiliative interactions between group members (MondragónCeballos 2001). Although the phenomenon has been documented in a number of species (Seyfarth 1980; Aureli et al. 1992; Massen et al. 2014; Mielke et al. 2017; Schneider and Krueger 2012), little is known about its role in shaping social relationships between other individuals. For example, can systematic interference in the affiliative interactions of a new immigrant prevent the formation of a friendly relationship with the resident animals? Overall, this is a largely neglected topic. Recent evidence, however, seems to indicate that interference in grooming interactions in mandrills can contribute to generate the pattern of rank-related access to dominant individuals that is commonly observed in a variety of primate species (Schino and Lasio 2018; cf. Seyfarth 1977).

Generally speaking, at least in some species of group-living animals, individuals need to take into account the behavior of third parties when making decisions about social interactions. For example, weaker animals are unlikely to be attacked if they are protected by a stronger ally, and attractive social partners cannot be easily accessed if there is interference by dominants.

\section{Aspects of social organization relevant to social complexity}

According to Kappeler and van Schaik (2002), social organization refers to the size, sexual composition, and spatiotemporal cohesion of the group. Studies of social complexity have focused mainly on group size (Kappeler 2019, topical collection on Social complexity). Here, we deal with the degree of fission-fusion dynamics, which relates to spatiotemporal cohesion and the temporary changes in size and composition. The term fission-fusion was introduced to describe the grouping patterns of species that fission into subgroups as a temporary adjustment to food availability and then fuse back again (Kummer 1971). A reconsideration of this concept made it broader, encompassing the three aspects of social organization. Accordingly, fission-fusion dynamics are considered as a characteristic of any social system (Aureli et al. 2008). Individuals in rather cohesive groups have a low degree of such dynamics. In contrast, individuals in groups with a high degree of fission-fusion dynamics are rarely all together, as they frequently fission and fuse in subgroups of variable membership, or show high temporal variation in spatial cohesion (Aureli et al. 2008). The critical aspect of fission-fusion dynamics for social complexity is that such dynamics influence the opportunity group members have to interact with one another because of changes in spatial cohesion, subgroup size and composition, introducing uncertainty about their social relationships, and the social context in which they interact (Ramos-Fernandez et al. 2018).

In this respect, fission-fusion dynamics are a modulator of social intercourse. For example, two individuals may have a prolonged separation when they spend extended time in different subgroups. The absence of interaction between them can be challenging with respect to maintaining their relationship (see below). The absence of some individuals can also be challenging when making decisions about interacting if certain partners are preferred for certain tasks (e.g., cooperation: Melis et al. 2006; Weidt et al. 2014). Both situations may be sources of uncertainty as the individuals cannot interact as usual, but they need to flexibly adapt to the changing situations. A high degree of fission-fusion dynamics can also increase social complexity when considering exchanges based on the biological market theory (Noë and Hammerstein 1995) as an individual's value in terms of what she can provide to others in a given context depends on her value relative to that of others. In highly cohesive groups, each individual's relative value is rather stable, but in groups with a high degree of fission-fusion dynamics, each individual's relative value depends on who else is around. This situation makes beneficial exchanges more flexible and uncertain, and the decision process more complex.

The change in subgroup composition due to fission-fusion dynamics affects the social environment where two 
individuals interact. As third parties may influence the interactions between two individuals (see above), the way an individual interacts with another may depend on who else is in the subgroup. For example, an individual may be less tolerant toward a group member if a long-term ally of that group member is not present in the subgroup. Similarly, variable subgroup composition influences audience effects (Zajonc 1965; McGregor 2005). For example, spider monkey males tend to reduce the affiliation they exchange with each other if at least one more male is present in the subgroup (Saldaña Sánchez et al. unpublished data).

Hence, the degree of fission-fusion dynamics modulates how group members interact with one another because the presence of potential partners, potential supporters, and potential eavesdroppers is variable depending on subgroup composition and spatial cohesion. The degree of fission-fusion dynamics therefore contributes to the complexity that individuals face because of variation within the same relationship and across relationships with different group members by adding a shorter-term source of variation. This source of variation applies to the same relationship depending on how the two partners adjust their interactions with respect to how long they have been separated and who else is present in terms of potential supporters and eavesdroppers. Similarly, the potential changes in their own and each partner's relative value depending on the presence of others is a source of short-term variation across social relationships.

\section{How individuals cope with social complexity}

The social complexity highlighted above leads to problems individuals need to solve to function effectively in their social environment. Before addressing these problems, we need to clarify an issue related to Hinde's $(1976,1979)$ conceptualization of social relationships as emerging from the patterning of interactions between individuals over time. It has been argued that the temporal component introduces a prospective element in which individuals are motivated to cultivate social relationships for future benefits (Henzi and Barrett 2007). Henzi and Barrett (2007) claimed that as prospective reasoning is beyond the abilities of animals other than humans, the concept of social relationships is superfluous in understanding animals' social decision-making. Contrary to this argument, we believe Hinde's $(1976,1979)$ framework does not imply that animals are motivated by anticipated benefits or are conscious of the long-term outcome of their actions. In fact, as animals interact with others based on their history of interactions, the temporal component deals with the past, and not the future (Aureli et al. 2012; Seyfarth and Cheney 2012).

Being able to respond appropriately to the actions of their partners based on their past interactions (i.e., their social relationships) clearly facilitates social intercourse. Given the variations within and across social relationships highlighted above, individuals need to modify their behavior according to the quality of their relationships with potential partners in a particular context. Thus, it is critical for animals to assess the quality of their social relationships. We have suggested that animals base this assessment on the information contained in the various interactions previously exchanged with each of their partners (Aureli and Schaffner 2002; Aureli et al. 2012). They then need to integrate information about the frequency, duration, and consequences of different types of interactions with each of their partners, convert it into some kind of common currency, and update this information across time. This kind of bookkeeping seems rather demanding. There are two broad categories of mechanisms animals may use to achieve this task and cope with problems related to the social complexity they experience in their groups. In the next subsections, we address each of them. Note that although emotions and cognitive abilities are clearly interlinked, here, we treat emotional mediation and cognitive enhancement separately to facilitate their description.

\section{Emotional mediation}

Emotions can provide individuals with a timely relationship assessment to guide social decisions (Aureli and Schaffner 2002; Schino and Aureli 2009). Such assessment can be achieved by considering the mediating role of emotions implicit in the concept of intervening variable (Hinde 1972; Aureli and Whiten 2003). A particular emotional state (without implying subjective feeling) would lead the individual to take a particular motivational stance, which constrains decision-making and influences behavior in a way that is appropriate to the situation (Aureli and Whiten 2003). The emotional experience of an individual is certainly affected by the types, frequencies, and patterning of previous interactions with other group members (Aureli and Schaffner 2002; Aureli and Whiten 2003; Schino and Aureli 2009; Seyfarth and Cheney 2012). Emotional states may then provide a crucial integration of the information contained in the various interactions between two partners and may change over time depending on the interactions exchanged. Although the neuroendocrine mechanisms underlying the modulation of these partner-specific emotional states are largely unknown, recent evidence points to a role for oxytocin, which has been shown to be released in association with the exchange of friendly interactions (grooming and food sharing) in chimpanzees (Pan troglodytes) (Crockford et al. 2013; Wittig et al. 2014).

The resulting partner-dependent emotional state can therefore be functionally equivalent to the processes of bookkeeping mentioned above, which is needed for continuous relationship assessment (Aureli et al. 2012). For example, the anxiety former opponents experience after an aggressive interaction is affected by the quality of their relationship (Aureli 1997; 
Kutsukake and Castles 2001; Cooper et al. 2007; Koski et al. 2007). Such anxiety may then be the proximate mechanism for reconciliation between former opponents, which is more likely to occur between individuals with certain types of relationships (e.g., kin, supporters, partners with higher affiliation: see above). Thus, these partner- and context-dependent emotional states can be at the core of the individual assessment of the variation within and across social relationships and be instrumental in the successful navigation of the social complexity thus generated.

\section{Cognitive enhancement}

Although emotional mediation can provide solutions to most problems due to the complexity individuals face in relation to variation across and within their social relationships, there are problems posed by the social environment that may require greater degrees of cognitive sophistication.

A first set of such problems is posed by the varied influences that third parties can have on social relationships. One example is the process of rank acquisition in juvenile macaques and hyaenas described above. Group members have to learn that a given juvenile cannot be attacked despite her small size and low physical power because her high-ranking mother can come to help her. The learning is likely based on a discrimination process. Group members learn to interact submissively toward juveniles with higher-ranking mothers and to act as dominant toward juveniles with lower-ranking mothers.

In species characterized by low degrees of fission-fusion dynamics, the continuous presence of the mothers makes learning how to interact with different juveniles a relatively straightforward process that can be based on simple discrimination. In species characterized by a higher degree of fissionfusion dynamics, or that live in environments with lower visibility, group members may use conditional discrimination to learn to interact submissively with the offspring of higherranking mothers only when the mother is present/nearby. Macaques, though living in rather cohesive groups, seem to be able to take advantage of the possibilities offered by the temporary absence of the mother. Chapais' (1988) experimental studies showed how juveniles separated from their mother fall rapidly in rank below adult females that would never dare to attack them in their mother's presence. It is unknown whether in species living in less cohesive groups the process of rank acquisition is less influenced by the mother's interference. In principle, individuals living in groups characterized by a high degree of fission-fusion dynamics are expected to be particularly good at solving problems of conditional discrimination, because the varying presence of third parties is a characteristic of their social environment. Another ability that should be enhanced in such groups is self-control (MacLean et al. 2014) as individuals should refrain from interacting as usual when they are reunited with other group members after subgroup fusion. Given the change in the social environment after fusion, it is beneficial for individuals to inhibit prepotent responses, assess the new social situation and flexibly adjust their interactions (Aureli et al. 2008). There is experimental evidence that individuals of species characterized by a higher degree of fission-fusion dynamics show more inhibitory control and more effective flexible responses in the physical and social domains than individuals of species characterized by a lower degree of fission-fusion dynamics (Amici et al. 2008, 2009,2018 ), although whether these species also excel in solving problems of conditional discrimination is currently unknown.

In fact, variable subgroup composition is likely to pose several problems that may require specific cognitive adaptations. The mere need to behave consistently toward group members may be made more difficult by their potentially long absence from the immediate social surroundings. For example, two animals sharing an amicable relationship may remain separated for several days and thus may not have any opportunity for exchanging grooming or other affiliative interactions. On meeting again after subgroup fusion, they need to be able to resume a friendly intercourse, which may require both specific greeting ceremonies (e.g., embraces in spider monkeys: Aureli and Schaffner 2007) and enhanced "memory." We are using quotation marks here because what is really needed is an increase in the time during which past positive interactions retain their influence on the attitude shown toward a partner. To be able to do so may imply enhanced episodic or semantic memory (Schacter and Addis 2007; Eysenck 2012) as well as longer-lasting emotional consequences (for emotional mediation: see above; cf. Aureli et al. 2008). Prolonged separation could also pose a challenge in the reciprocation of cooperative interactions (Schino 2007; Schino and Aureli 2008). In addition to enhanced "memory," animals may cope with this challenge by shortening the timeframe of social exchange to reduce the likelihood of errors (Barrett et al. 1999).

Given the influence third parties can have on social interactions, species characterized by a high degree of fissionfusion dynamics may take advantage of their variable presence by making active decisions about subgroup membership. For example, one can speculate that an individual might decide to join the subgroup including individual $\mathrm{A}$ in order to attack it, but to avoid joining that subgroup if individual B (an ally of A's) is also present. There is evidence for subgroup membership preference when subgroups fission. For example, spider monkeys fission into the same subgroup with group members with whom they have a relationship characterized by higher levels of compatibility and value and lower levels of insecurity (Busia et al. 2017). Thus, we can further speculate that it could be advantageous for individuals to engineer subgroup membership (Aureli et al. 2008). For example, they can 
select to be in subgroups with the strongest and more committed group members who can protect them or can prefer subgroups with the weakest group members, so to be the best protection provider and thus receive a disproportionate amount of services (e.g., grooming or mating opportunities) in exchange (Noë and Hammerstein 1995; Barrett et al. 2003). Note that this kind of hypothetical strategies would require some form of planning, and it is therefore possible that a high degree of fission-fusion dynamics may require cognitive abilities related to planning (Aureli et al. 2008), although it is unclear whether such dynamics may select for these cognitive abilities or whether a high degree of fission-fusion dynamics is only possible in species that already have such abilities.

We have been concerned with how animals perceive complexity in their own social relationships, and with how they deal with this complexity. A separate set of questions relates to how (and if) animals deal with complexity in the social relationships between other group members, and to how they deal with this complexity. As we argued that the extent of social complexity is linked to relationship differentiation (cf. Bergman and Beehner 2015), these latter questions have been addressed in a number of other reviews (e.g., Seyfarth and Cheney 2012; see Bond et al. 2003 and Grosenick et al. 2007 for examples of nonprimate species) and we refer the interested reader to such reviews. Here, we only note that in species that do take into account the relationships between others in their interacting, the extent to which this impacts the complexity faced by individuals depends again on the degree of differentiation of these social relationships.

\section{Conclusions}

The approach we took in our review of various sources of social complexity provided a fresh look at several issues. The first issue is that, although the views of social complexity from the outside and from within are complementary, they may sometimes reach opposite conclusions. For example, viewed from the outside, a social structure comprising multiple clusters, each consisting of one matriline, would appear more complex than a social structure without such clusters. However, the relative complexity of the two structures may be reversed when we take the individual group member's perspective. In the clustered social structure, an individual could categorize other group members into the various clusters (e.g., matriline A, matriline $\mathrm{B}$, matriline $\mathrm{C}$ ) or simply into two sets (e.g., individuals belonging to her own matriline and individuals belonging to the other matrilines). In contrast, in the non-clustered social structure, individuals may need to differentiate their relationships with other group members based on the degree of kinship they share with each of them. The latter is clearly more challenging for the decision-making process as it would impose a higher degree of complexity to the individual because the relationship differentiation would be based on the degree of kinship as a continuous variable or on multiple (ordered) categories of kin, instead of being simply based on a dichotomous distinction.

A second issue is that there has recently been a certain amount of emphasis on the stability of social relationships (Silk 2007). It is certainly important to remark that there are some relationships that are stable for extended periods of time (Connor et al. 2001; Silk et al. 2006; Mitani 2009; Stanley et al. 2018), but this emphasis may also overshadow what the typical situation is. Following Hinde's framework, social relationships are dynamic and can change over time. Thus, stability can be considered to be more the exception than the norm. For the purpose of our paper, dealing with stable relationships is clearly less complex for a given group member than dealing with social relationships that change over time.

A third issue is related to the overall approach of the outstanding work done in the last 15 years documenting the fitness benefits of social relationships in a variety of species (e.g., Silk et al. 2003; Cameron et al. 2009; Schülke et al. 2010; Riehl and Strong 2018). It is certainly challenging to extract meaningful measures of the quality of social relationships from long-term datasets, as the detail and intensity of data collection has likely changed over time. Thus, most studies addressing fitness benefits of social relationships have combined a handful of measures of social interactions in one single index. Using this kind of index has made the analysis of the impact of relationship quality on various fitness metrics easier because there was only one measure representing social relationships. Still, what we have reviewed in this paper shows that this approach oversimplifies the nature of social relationships (Schweinfurth et al. 2017). When we do not combine different social interactions ourselves into arbitrary metrics, but we use statistical tools to combine them (e.g., principal component analysis), the general outcome is not a single measure, but multiple components of relationship quality (Cords and Aureli 2000; Fraser et al. 2008). This is a critical aspect for studying social complexity as it means that the degree of relationship differentiation does not vary along a single axis. Therefore, the problems individuals face are more complex because social relationships are multifaceted. It remains also to be assessed how the different components of social relationships relate to reproductive success and thus to the fitness benefits of sociality.

A fourth issue has to do with how to study the link between social complexity and cognition. As we mentioned, there is a great emphasis in understanding how social complexity emerges from individuals following simple rules (e.g., He et al. 2019; Kappeler 2019; Storms et al. 2019, all in topical collection on Social complexity). However, this view of social complexity from the outside does not seem appropriate to study the implications of complexity for cognition. If we are interested in which cognitive abilities may be enhanced because of social complexity, we need to take the individual group member's perspective into account and 
examine the degree of complexity the individual faces and what cognitive abilities the individual can use to successfully solve the problems posed by a given social context. Recognizing the differences between the view from the outside and the view from within would substantially contribute to identifying the critical variables of social complexity and cognition to use, instead of relying on generic proxies (e.g., group size: S.D. Healy pers. comm.).

In conclusion, we recommend researchers to be aware of the two possible views that can be adopted when studying social complexity, and to continue with the view they previously used only after evaluating whether it is the most appropriate for their research question (e.g., not to follow the view from outside if the research question entails understanding how animals perceive and deal with social complexity). In this respect, we expect a shift from the predominant view from the outside to the view from within when more appropriate. We therefore propose that a refined view of social relationships is needed to study the social complexity faced by individual group members. This view needs to take into consideration variation within and between social relationships, their dynamic and multifaceted nature, and the possible role of third parties. We also emphasize the potential contribution of the view from within to the study of social complexity and cognition. For a real appreciation of social complexity, we need more studies on a variety of taxa using similar terminology and approach (cf. Kappeler 2019, topical collection on Social complexity). These studies would provide evidence about the extent of similarities across taxa and allow phylogenetically controlled comparative analyses (e.g., Fuentes-González and Martins 2019, topical collection on Social complexity) to examine the evolution of key sources of social complexity.

Acknowledgments We would like to thank Peter Kappeler for the invitation to the 11th Göttinger Freilandtage "Social Complexity - Patterns, Processes and Evolution" and his team for the smooth running of the productive and pleasant meeting. We thank the guest editor and two anonymous reviewers for constructive comments. FA is grateful to the Consejo Nacional por la Ciencia y la Tecnología (CONACyT) for financial support.

\section{Compliance with ethical standards}

Conflict of interest The authors declare that they have no conflict of interest.

Open Access This article is distributed under the terms of the Creative Commons Attribution 4.0 International License (http:// creativecommons.org/licenses/by/4.0/), which permits unrestricted use, distribution, and reproduction in any medium, provided you give appropriate credit to the original author(s) and the source, provide a link to the Creative Commons license, and indicate if changes were made.

Publisher's Note Springer Nature remains neutral with regard to jurisdictional claims in published maps and institutional affiliations.

\section{References}

Altizer S, Nunn CL, Thrall PH et al (2003) Social organization and parasite risk in mammals: integrating theory and empirical studies. Annu Rev Ecol Evol S 34:517-547

Altmann J (1980) Baboon mothers and infants. University of Chicago Press, Chicago

Amici F, Aureli F, Call J (2008) Fission-fusion dynamics, behavioral flexibility and inhibitory control in primates. Curr Biol 18:14151419

Amici F, Call J, Aureli F (2009) Variation in withholding of information in three monkey species. Proc R Soc Lond B 276:3311-3318

Amici F, Call J, Watzek J, Brosnan S, Aureli F (2018) Social inhibition and behavioural flexibility when the context changes: a comparison across six primate species. Sci Rep 8:3067

Anderson C, McShea DW (2001) Individual versus social complexity, with particular reference to ant colonies. Biol Rev 76:211-237

Asensio N, Korstjens AH, Schaffner CM, Aureli F (2008) Intragroup aggression, fission-fusion dynamics and feeding competition in spider monkeys. Behaviour 145:983-1001

Aureli F, Schaffner CM (2007) Aggression and conflict management at fusion in spider monkeys. Biol Lett 3:147-149

Aureli F, de Waal FBM (2000) Natural conflict resolution. University of California Press, Berkeley

Aureli F, van Schaik CP, van Hooff JARAM (1989) Functional aspects of reconciliation among captive long-tailed macaques (Macaca fascicularis). Am J Primatol 19:39-51

Aureli F, Cozzolino R, Cordischi C, Scucchi S (1992) Kin-oriented redirection among Japanese macaques: an expression of a revenge system? Anim Behav 44:283-291

Aureli F (1997) Post-conflict anxiety in nonhuman primates: The mediating role of emotion in conflict resolution. Aggress Behav 23:315328

Aureli F, Schaffner CM (2002) Relationship assessment through emotional mediation. Behaviour 139:393-420

Aureli F, Cords M, van Schaik CP (2002) Conflict resolution following aggression in gregarious animals: a predictive framework. Anim Behav 64:325-343

Aureli F, Whiten A (2003) Emotions and behavioral flexibility. In: Maestripieri D (ed) Primate psychology - the mind and behavior of human and nonhuman primates. Harvard University Press, Cambridge $\mathrm{p} 289-323$

Aureli F, Schaffner CM, Boesch C et al (2008) Fission-fusion dynamics: new research frameworks. Curr Anthropol 48:627-654

Aureli F, Fraser ON, Schaffner CM, Schino G (2012) The regulation of social relationships. In: Mitani J, Call J, Kappeler P, Palombit R, Silk $\mathrm{J}$ (eds) The evolution of primate societies. University of Chicago Press, Chicago, pp 531-551

Baker KC, Aureli F (2000) Coping with conflict during initial encounters in chimpanzees. Ethology 106:527-541

Ballerini M, Cabibbo N, Candelier R et al (2008) Interaction ruling animal collective behavior depends on topological rather than metric distance: evidence from a field study. P Natl Acad Sci USA 105: 1232-1237

Barrett L, Henzi SP, Weingrill T, Lycett JE, Hill RA (1999) Market forces predict grooming reciprocity in female baboons. Proc R Soc Lond B 266:665-670

Barrett L, Henzi P, Dunbar RIM (2003) Primate cognition: from "what now?" to "what if?". Trends Cogn Sci 7:494-497

Bascompte J, Solé RV (1995) Rethinking complexity: modelling spatiotemporal dynamics in ecology. Trends Ecol Evol 10:361-366

Bashaw MJ, Bloomsmith MA, Maple T, Bercovitch FB (2007) The structure of social relationships among captive female giraffe (Giraffa camelopardalis). J Comp Psychol 121:46-53 
Bergman TJ, Beehner JC (2015) Measuring social complexity. Anim Behav 103:203-209

Bergman TJ, Beehner JC, Cheney DL, Seyfarth RM (2003) Hierarchical classification by rank and kinship in baboons. Science 5648:1234 1236

Bonabeau E, Theraulaz G, Deneubourg JL, Aron S, Camazine S (1997) Self-organization in social insects. Trends Ecol Evol 12:188-193

Bond AB, Kamil AC, Balda RP (2003) Social complexity and transitive inference in corvids. Anim Behav 65:479-487

Busia L, Schaffner CM, Aureli F (2017) Relationship quality affects fission decisions in wild spider monkeys (Ateles geoffroyi). Ethology 123:405-411

Cameron EZ, Setsaas TH, Linklater WL (2009) Social bonds between unrelated females increase reproductive success in feral horses. $\mathrm{P}$ Natl Acad Sci USA 106:13850-13853

Chapais B (1988) Experimental matrilineal inheritance of rank in female Japanese macaques. Anim Behav 36:1025-1037

Chapais B, Gauthier C, Prud'homme J (1995) Dominance competition through affiliation and support in Japanese macaques: an experimental study. Int J Primatol 16:521-536

Chapais B, Savard L, Gauthier C (2001) Kin selection and the distribution of altruism in relation to degree of kinship in Japanese macaques (Macaca fuscata). Behav Ecol Sociobiol 49:493-502

Chialvo DR (2010) Emergent complex neural dynamics. Nat Phys 6: 744-750

Chu D, Strand R, Fjelland R (2003) Theories of complexity-common denominators of complex systems. Complexity 8:19-30

Connor RC, Heithaus MR, Barre LM (2001) Complex social structure, alliance stability and mating access in a bottlenose dolphin 'superalliance'. Proc R Soc Lond B 268:263-267

Cooper M, Aureli F, Singh M (2007) Sex differences in reconciliation and post- conflict anxiety in bonnet macaques. Ethology 113:26-38

Cords M, Aureli F (2000) Reconciliation and relationship qualities. In: Aureli F, de Waal FBM (eds) Natural conflict resolution. University of California Press, Berkeley, pp 177-198

Crockford C, Wittig RM, Langergraber K, Ziegler TE, Zuberbühler K, Deschner T (2013) Urinary oxytocin and social bonding in related and unrelated wild chimpanzees. Proc R Soc B 280:20122765

Dunbar RIM (2012) Bridging the bonding gap: the transition from primates to humans. Philos Trans R Soc B 367:1837-1846

Durrell JL, Sneddon IA, O'Connell NE, Whitehead H (2004) Do pigs form preferential associations? Appl Anim Behav Sci 89:41-52

Eysenck MW (2012) Fundamentals of cognition. Psychology Press, New York

Fischer J, Farnworth MS, Sennhenn-Reulen H, Hammerschmidt K (2017) Quantifying social complexity. Anim Behav 130:57-66

Fraser ON, Bugnyar T (2010) The quality of social relationships in ravens. Anim Behav 79:927-933

Fraser ON, Schino G, Aureli F (2008) Components of relationship quality in chimpanzees. Ethology 114:834-843

Freeberg TM, Dunbar RIM, Ord TJ (2012) Social complexity as a proximate and ultimate factor in communicative complexity. Philos Trans R Soc B 367:1785-1801

Fuentes-González JA, Martins EP (2019) Phylogenies and social complexity. Behav Ecol Sociobiol. https://doi.org/10.1007/s00265-018-2614-3

Ganslosser U (1993) Stages in formation of social relationships: an experimental investigation in kangaroos (Macropodoidea: Mammalia). Ethology 94:221-247

Griffin AS, West SA (2003) Kin discrimination and the benefit of helping in cooperatively breeding vertebrates. Science 302:634-636

Grosenick L, Clement TS, Fernald RD (2007) Fish can infer social rank by observation alone. Nature 445:429-432

Gueron S, Levin SA (1993) Self-organization of front patterns in large wildebeest herds. J Theor Biol 165:541-552

Harcourt A, de Waal FBM (1992) Coalitions and alliances in humans and other animals. Oxford University Press, Oxford
He P, Maldonado-Chaparro AA., Farine DR (2019) The role of habitat configuration in shaping social structure: a gap in studies of animal social complexity. Behav Ecol Sociobiol. https://doi.org/10.1007/ s00265-018-2602-7

Hemelrijk C (2013) Simulating complexity of animal social behaviour. In: Edmonds B, Meyer R (eds) Simulating social complexity. Springer, Berlin, pp 581-615

Henzi SP, Barrett L (2007) Coexistence in female- bonded primate groups. Adv Study Behav 37:43-81

Hinde RA (1972) Concepts of emotion. Ciba Foundation Symposia 8:313

Hinde RA (1976) Interactions relationships and social structure. Man 11: $1-17$

Hinde RA (1978) Dominance and role - two concepts with dual meanings. J Soc Biol Struct 1:27-38

Hinde RA (1979) Towards understanding relationships. Academic Press, London

Hinde RA (1983a) A conceptual Framework. In: Hinde RA (ed) Primate social relationships: an integrated approach. Blackwell Scientific Publications, Oxford, pp 1-7

Hinde RA (ed) (1983b) Primate social relationships: an integrated approach. Blackwell Scientific Publications, Oxford

Hinde RA, White LE (1974) Dynamics of a relationship: rhesus motherinfant ventro-ventral contact. J Comp Physiol Psychol 86:9-23

Holekamp KE, Sakai ST, Lundrigan BL (2007) Social intelligence in the spotted hyena (Crocuta crocuta). Philos Trans R Soc B 362:523538

Janson CH, Baldovino MC, Di Bitetti MS (2012) The group life cycle and demography of brown capuchin monkeys (Cebus [apella] nigritus) in Iguazù National Park, Argentina. In: Kappeler PM, Watts DP (eds) Long-term field studies of primates. Springer, Berlin, pp 185-212

Johnson N (2009) Simply complexity: a clear guide to complexity theory. Oneworld, Oxford

Kapheim KM (2019) Understanding social complexity in insects as a synthesis of Tinbergen's four questions. Behav Ecol Sociobiol. https://doi.org/10.1007/s00265-018-2606-3

Kappeler PM (2019) A framework for studying social complexity. Behav Ecol Sociobiol. https://doi.org/10.1007/s00265-018-2601-8

Kappeler PM, van Schaik CP (2002) Evolution of primate social systems. Int J Primatol 23:707-740

Kawai M (1958) On the rank system in a natural troop of Japanese monkey (1): the basic and dependent rank. Primates 1:111-130 (in Japanese)

Koski SE, Koops K, Sterck EHM (2007) Reconciliation, relationship quality, and postconfl ict anxiety: testing the integrated hypothesis in captive chimpanzees. Am J Primatol 69:158-172

Kummer H (1971) Primate societies: group techniques of ecological adaptation. Aldine, Chicago

Kummer H (1975) Rules of dyad and group formation among captive baboons (Theropithecus gelada). In: Proceedings of the 5th Congress of the International Primatological Society. Karger, Basel, pp 129-160

Kutsukake N (2009) Complexity, dynamics and diversity of sociality in group-living mammals. Ecol Res 24:521-531

Kutsukake N, Castles DL (2001) Reconciliation and variation in postconflict stress in Japanese macaques (Macaca fuscata fuscata): testing the integrated hypothesis. Anim Cogn 4:259-268

Lukas D, Clutton-Brock T (2019) Social complexity and kinship in animal societies. Ecol Lett 21:1129-1134

MacLean EL, Hare B, Nunn CL et al (2014) The evolution of self-control. P Natl Acad Sci USA 111:E2140-E2148

Massen JJ, Szipl G, Spreafico M, Bugnyar T (2014) Ravens intervene in others' bonding attempts. Curr Biol 24:2733-2736 
Matoba T, Kutsukake N, Hasegawa T (2013) Head rubbing and licking reinforce social bonds in a group of captive African lions, Panthera leo. PLoS One 8:e73044

McGregor PK (2005) Animal communication networks. Cambridge University Press, Cambridge

Melis AP, Hare B, Tomasello M (2006) Chimpanzees recruit the best collaborators. Science 311:1297-1300

Mielke A, Samuni L, Preis A, Gogarten JF, Crockford C, Wittig RM (2017) Bystanders intervene to impede grooming in Western chimpanzees and sooty mangabeys. R Soc Open Sci 4:171296

Mitani JC (2009) Male chimpanzees form enduring and equitable social bonds. Anim Behav 77:633-640

Mondragón-Ceballos R (2001) Interfering in affiliations: sabotaging by stumptailed macaques, Macaca arctoides. Anim Behav 62:11791187

Nadel L, Stein O (1991) 1990 lectures in complex systems-Santa Fe Institute in the Sciences of Complexity. Addison-Wesley Publishing Company, Redwood City, CA

Noë R, Hammerstein P (1995) Biological markets. Trends Ecol Evol 10: 336-339

Palagi E, Antonacci D, Norscia I (2008) Peacemaking on treetops: first evidence of reconciliation from a wild prosimian (Propithecus verreauxi). Anim Behav 76:737-747

Palombit RA, Cheney DL, Fischer J, Johnson S, Rendall D, Seyfarth RM, Silk JB (2000) Male infanticide and defense of infants in chacma baboons. In: van Schaik CP, Janson CH (eds) Infanticide by males and its implications. Cambridge University Press, Cambridge, pp $123-152$

Parrish JK, Edelstein-Keshet L (1999) Complexity, pattern, and evolutionary trade-offs in animal aggregation. Science 284:99-101

Perry S, Barrett HC, Manson JH (2004) White-faced capuchin monkeys show triadic awareness in their choice of allies. Anim Behav 67: $165-170$

Petit O, Thierry B (1994) Aggressive and peaceful interventions in conflicts in Tonkean macaques. Anim Behav 48:1427-1436

Ramos-Fernandez G, Boyer D, Gomez VP (2006) A complex social structure with fission-fusion properties can emerge from a simple foraging model. Behav Ecol Sociobiol 60:536-549

Ramos-Fernandez G, King AJ, Beehner JC et al (2018) Quantifying uncertainty due to fission-fusion dynamics as a component of social complexity. Proc R Soc B 285:20180532

Reinhardt V, Reinhardt A (1981) Cohesive relationships in a cattle herd (Bos indicus). Behaviour 77:121-155

Reynolds CW (1987) Flocks, herds, and schools: a distributed behavioral model. Comput Graph 21:25-34

Riehl C, Strong MJ (2018) Stable social relationships between unrelated females increase individual fitness in a cooperative bird. Proc R Soc B 285:20180130

Riveros JC, Schaffner CM, Aureli F (2017) You are not welcome: social exchanges between female spider monkeys (Ateles geoffroyi). Int J Primatol 38:856-871

Romero T, Colmenares F, Aureli F (2009) Testing the function of reconciliation and third-party affiliation for aggressors in hamadryas baboons (Papio hamadryas hamadryas). Am J Primatol 71:60-69

Schacter DL, Addis DR (2007) The cognitive neuroscience of constructive memory: remembering the past and imagining the future. Philos Trans R Soc B 362:773-786

Schino G (2001) Grooming, competition and social rank among female primates: a meta-analysis. Anim Behav 62:265-271

Schino G (2007) Grooming and agonistic support: a meta- analysis of primate reciprocal altruism. Behav Ecol 18:115-120

Schino G, Aureli F (2008) Grooming reciprocation among female primates: a meta-analysis. Biol Lett 4:9-11

Schino G, Aureli F (2009) Reciprocal altruism in primates: partner choice, cognition and emotions. Adv Study Behav 39:45-69
Schino G, Lasio F (2018) Competition for grooming partners and interference in affiliation among female mandrills. Ethology (published online). https://doi.org/10.1111/eth.12763

Schino G, Maestripieri D, Scucchi S, Turillazzi PG (1990) Social tension in familiar and unfamiliar pairs of long-tailed macaques. Behaviour 113:264-272

Schino G, D'Amato FR, Troisi A (1995) Mother-infant relationships in Japanese macaques - sources of interindividual variation. Anim Behav 49:151-158

Schino G, Tiddi B, Polizzi Di Sorrentino E (2006) Simultaneous classification by rank and kinship in Japanese macaques. Anim Behav 71: 1069-1074

Schino G, Tiddi B, Polizzi di Sorrentino E (2007) Agonistic support in juvenile Japanese macaques: cognitive and functional implications. Ethology 113:1151-1157

Schneider G, Krueger K (2012) Third-party interventions keep social partners from exchanging affiliative interactions with others. Anim Behav 83:377-387

Schülke O, Ostner J, Bhagavatula J, Vigilant L (2010) Social bonds enhance reproductive success in male macaques. Curr Biol 20: 2207-2219

Schweinfurth MK, Neuenschwander J, Engqvist L, Schneeberger K, Rentsch AK, Gygax M, Taborsky M (2017) Do female Norway rats form social bonds? Behav Ecol Sociobiol 71:1-9

Seyfarth RM (1977) A model of social grooming among adult female monkeys. J Theor Biol 65:671-698

Seyfarth RM (1980) The distribution of grooming and related behaviours among adult female vervet monkeys. Anim Behav 28:798-813

Seyfarth RM, Cheney DL (2012) The evolutionary origin of friendship. Annu Rev Psychol 63:153-177

Shaw E (1970) Schooling in fishes: critique and review. In: Aronson LR, Tobach E, Lehrman DS, Rosenblatt JS (eds) Development and evolution of behavior. Freeman, San Francisco, pp 452-480

Sheehan MJ, Straub MA, Tibbetts EA (2014) How does individual recognition evolve? Comparing responses to identity information in Polistes species with and without individual recognition. Ethology 120:169-179

Silk JB (1999) Male bonnet macaques use information about third-party rank relationships to recruit allies. Anim Behav 58:45-51

Silk JB (2007) The adaptive value of sociality in mammalian groups. Philos Trans R Soc B 362:539-559

Silk JB, Alberts SC, Altmann J (2003) Social bonds of female baboons enhance infant survival. Science 302:1331-1334

Silk JB, Alberts SC, Altmann J (2006) Social relationships among adult female baboons (Papio cynocephalus) II. Variation in the quality and stability of social bonds. Behav Ecol Sociobiol 61:197-204

Silk J, Cheney D, Seyfarth R (2013) A practical guide to the study of social relationships. Evol Anthropol 22:213-225

Simpson MJA, Howe S (1980) The interpretation of individual differences in the behaviour of rhesus monkey infants. Behaviour 72:127155

Slater KY, Schaffner CM, Aureli F (2007) Embraces for infant handling in spider monkeys: evidence for a biological market? Anim Behav 74:455-461

Smith JE, Van Horn RC, Powning KS, Cole AR, Graham KE, Memenis SK, Holekamp KE (2010) Evolutionary forces favoring intragroup coalitions among spotted hyenas and other animals. Behav Ecol 21: 284-303

Stanley CR, Mettke-Hofmann C, Hager R, Shultz S (2018) Social stability in semiferal ponies: networks show interannual stability alongside seasonal flexibility. Anim Behav 136:175-184

Storms RF, Carere C, Zoratto F, Hemelrijk CK (2019) Complex collective motion: escape patterns in starling flocks under predation. Behav Ecol Sociobiol. https://doi.org/10.1007/s00265-018-2609-0

Talbot LM, Talbot MH (1963) The wildebeest in Western Masailand, East Africa. Wildl Monogr 12:8-88 
Tinbergen N (1963) On aims and methods of ethology. Z Tierpsychol 20: 410-433

Trivers RL (1974) Parent-offspring conflict. Am Zool 14:249-264

de Waal FBM (1982) Chimpanzee politics. Johns Hopkins University Press, Washington

de Waal FBM (1986) The integration of dominance and social bonding in primates. Q Rev Biol 61:459-479

de Waal FBM, Tyack PL (2003) Animal social complexity. Harvard University Press, Cambridge

de Waal FBM, van Roosmalen A (1979) Reconciliation and consolation among chimpanzees. Behav Ecol Sociobiol 5:55-66

Watts DP (2006) Conflict resolution in chimpanzees and the valuablerelationships hypothesis. Int J Primatol 27:1337-1364
Weidt A, Lindholm AK, König B (2014) Communal nursing in wild house mice is not a by-product of group living: females choose. Naturwissenschaften 101:73-76

Weiss MN, Franks DW, Croft DP, Whitehead H (2019) Measuring social complexity from association data using mixture models. Behav Ecol Sociobiol. https://doi.org/10.1007/s00265-018-2603-6

Wittig RM, Crockford C, Deschner T, Langergraber KE, Ziegler TE, Zuberbühler K (2014) Food sharing is linked to urinary oxytocin levels and bonding in related and unrelated wild chimpanzees. Proc R Soc B 281:20133096

Zajonc RB (1965) Social facilitation. Science 149:269-274 